\title{
Choline: Clinical Nutrigenetic/Nutrigenomic Approaches for Identification of Functions and Dietary Requirements
}

\author{
Steven H. Zeisel \\ Nutrition Research Institute, Department of Nutrition, School of Public Health and School of Medicine, \\ University of North Carolina at Chapel Hill, Chapel Hill, N.C., USA
}

\begin{abstract}
Nutrigenetics/nutrigenomics (the study of the bidirectional interactions between genes and diet) is a rapidly developing field that is changing research and practice in human nutrition. Though eventually nutrition clinicians may be able to provide personalized nutrition recommendations, in the immediate future they are most likely to use this knowledge to improve dietary recommendations for populations. Currently, estimated average requirements are used to set dietary reference intakes because scientists cannot adequately identify subsets of the population that differ in requirement for a nutrient. Recommended intake levels must exceed the actual required intake for most of the population in order to assure that individuals with the highest requirement ingest adequate amounts of the nutrient. As a result, dietary reference intake levels often are set so high that diet guidelines suggest almost unattainable intakes of some foods. Once it is possible to identify common subgroups that differ in nutrient requirements using nutrigenetic/nutrigenomic profiling, targeted interventions and recommendations can be refined. In addition, when a large variance exists in response to a nutrient, statistical analyses often argue for a null effect. If responders could be differentiated from nonresponders based on nutrigenetic/nutrigenomic profiling, this statistical noise could be eliminated and the sensitivity of nutrition research greatly increased.
\end{abstract}

\section{Challenges for Clinical Nutrigenetics/Nutrigenomics}

The first challenge for developing clinical nutrigenetics/nutrigenomics is the growing misconception that only very large studies can develop evidence for associations between single nucleotide polymorphisms (SNPs) and phenotypes. The use of genomewide profiling of common single nucleotide polymorphisms (SNPs) to identify such 
associations has become common. These genome-wide association studies (GWAS) often screen thousands to millions of genes and their variants in thousands of subjects. In order to avoid the issue of multiplicity, and because of expected modest effect sizes, the scientific community has adopted strict definitions of statistical significance (e.g. $\mathrm{p}<5 \times 10^{-7}[1]$ ), which dictate the need for large sample sizes typically involving thousands of subjects. It is important to note that these definitions were adopted assuming an individual SNP has a small effect size and that large numbers of randomly selected SNPs are being screened for an association with a phenotype. Because of the enormous number of genotype-phenotype associations tested in a genome-wide study, spurious associations will substantially outnumber true ones unless rigorous statistical thresholds are applied; smaller $\mathrm{p}$ values generally provide greater support for a true association. However, standard Bonferroni correction is overly conservative because it assumes the independence of all tests performed, but in many association studies markers are not independent because they are in linkage disequilibrium.

Sadly, this growing consensus for requiring $\mathrm{p}$ values $<5 \times 10^{-7}$ makes clinical nutrigenetics/nutrigenomics virtually impossible. Inherently, such studies involve tens to hundreds but not thousands of subjects and often measure phenotype parameters that are not practically measured in large populations. If the phenotype to be explained is not easily detected in thousands of people, a population GWAS approach is not possible. For example, we later discuss studies on fatty liver that require controlled diet conditions and mass resonance imaging. It might be possible to perform such studies on hundreds of people, but certainly not on tens of thousands. For clinical nutrigenetics/nutrigenomics approaches to be viable we need to use study designs that allow less stringent $p$ values than are used for GWAS studies. The appropriate design elements have already been considered by the scientific panel that suggested the rigorous $p$ values for GWAS studies [1].

Reasons that are appropriate for lowering the threshold for calling a finding of a particular SNP-phenotype association are the selection of targeted SNPs based on knowledge of the underlying processes causing the phenotype (e.g. selecting the gene for endogenous biosynthesis of a nutrient when studying the phenotype associated with deficiency of the nutrient), or selecting SNPs that are likely to result in defective protein products (such as non-synonymous coding SNPs) [1]. Selection of SNPs for which there is credible laboratory evidence or a validated in silico prediction a priori permits accepting a less rigorous p value; however, creating a credible biological hypothesis post hoc is not acceptable [1]. The lowering of the threshold for positively identifying a particular SNP-phenotype association must be declared before initiation of the analysis and not once the analysis has begun [1]. Additional information gathered from laboratory techniques, bioinformatic tools and a priori biological insight should be used to provide plausibility for interpreting genetic association findings [1]. It is important to limit the number of candidate SNPs considered as the number of multiple comparisons made in the analysis drives the possibility of false discovery. Inherently, small sample sizes can provide imprecise or incorrect estimates of the magnitude of the observed effects; thus, 
the effect size must be large enough to stand out from such noise. An estimated effect size that is large (that is, with an odds ratio greater than 2) in a small but well-powered study can lend credence to an association, because unknown confounding factors are less likely to produce large effects [1]. Finally, replication of the association between SNP and phenotype in an independent study is important.

Thus, though some geneticists initially expressed doubts about results generated in clinical nutrigenetics/nutrigenomics because they reflexively expect large population studies with very small $\mathrm{p}$ values, there are reasonable study designs under which clinical nutrigenetics/nutrigenomics is not only possible but practical (targeted and small number of SNPs studied based on biological insights with SNPs that have a large effect size and results that can be replicated).

\section{Other Considerations before Undertaking Clinical Nutrigenetics/Nutrigenomics}

In GWAS or clinical nutrigenetics/nutrigenomic studies, a haplotype associated with the phenotype of interest can be identified. The identified polymorphism is rarely the actual phenotype-causing variant, but is more likely to be correlated, or in linkage disequilibrium with the functional SNP. Because SNP arrays do not assay every polymorphism in a genomic region, it is not possible to identify all the surrounding genetic variants that are correlated with the identified marker. However, we can define the boundaries within the gene where sequencing or subsequent fine-mapping experiments are appropriate [2].

\section{Prototype Experiment in Nutrigenetics/Nutrigenomics: Studies on Choline Deficiency}

The case study of the effects of genetic variation on dietary requirements for choline provides an excellent example of how clinical nutrigenetics/nutrigenomics can be used. In these studies, SNPs in the gene responsible for de novo biosynthesis of choline were associated with the risk for developing choline deficiency (phenotype). When young women were found to be resistant to developing choline deficiency, the role of estrogen in induction of choline biosynthesis was identified. In addition, the effects of choline on epigenetic regulation of gene expression were studied.

\section{Choline Metabolism}

Choline is involved in 3 major pathways: acetylcholine synthesis, methyl donation via betaine, and phosphatidylcholine synthesis [3]. Choline, via its irreversible oxidation to betaine [4], methylates homocysteine to form methionine. This is the precursor for 
synthesis of $S$-adenosylmethionine, the universal methyl donor needed for methylation of DNA, RNA and proteins. It is important to realize that choline, methionine and folate metabolism are inter-related at the step that homocysteine is methylated to form methionine [5]. Perturbing metabolism of one of the methyl-donors results in compensatory changes in the other methyl-donors due to the intermingling of these metabolic pathways [6-8]. Rats treated with the anti-folate, methotrexate, had diminished pools of choline metabolites in liver [7, 9]. Rats ingesting a choline-deficient diet had diminished tissue concentrations of methionine and $S$-adenosylmethionine [10] and doubled plasma homocysteine concentrations [11]. Humans who were choline deficient, even when fed adequate amounts of folic acid, had diminished capacity to methylate homocysteine [12].

Most of the foods we eat contain various amounts of choline, choline esters and betaine [13], and in 2004 the United States Department of Agriculture released a database on choline content in common foods (www.nal.usda.gov/fnic/foodcomp/Data/ Choline/Choline.pdf). The foods with greatest abundance of choline are of animal origin, especially eggs and liver. Human breast milk also is a good source of free choline and choline esters [14], and the manufacturers of infant formulas have recently modified the content of choline compounds to levels similar with the ones in human breast milk [14, 15]. The only source of choline other than diet is de novo biosynthesis of phosphatidylcholine catalyzed by phosphatidylethanolamine- $N$-methyltransferase (PEMT) in liver. This enzyme uses $S$-adenosylmethionine as a methyl donor and forms a new choline moiety [16].

Studies in humans show that dietary choline is required (reviewed in [3] and discussed later). In 1998, the US Institute of Medicine (Food and Nutrition Board) established for the first time adequate intake (AI) and tolerable upper intake limit values for choline, based on limited human studies [17] The AI is $550 \mathrm{mg} / 70 \mathrm{~kg}$ body weight, with upward adjustment in pregnant and lactating women; the upper intake limit ranges from $1,000 \mathrm{mg} /$ day in children to $3,500 \mathrm{mg} /$ day in adults [17]. For some age categories for which adequate data were missing, AI values have been set by extrapolating from adult values (for ages 1-18 years), and from infants (for ages 7-12 months) [17]. The 2005 NHANES survey reported that most people do not achieve the recommended AI for choline [18]. In participants from the Framingham Offspring Study the mean intake for total choline (energy adjusted) was below the AI values, with a mean intake of $313 \mathrm{mg} /$ day; moreover, there was an inverse association between choline intake and plasma total homocysteine concentration in subjects with low folate intakes [19].

\section{Consequences of Dietary Choline Deficiency in Humans}

Using a clinical methodology for phenotyping individuals with respect to their susceptibility to developing organ dysfunction when fed a low choline diet [12, 20-22], adult men and women (pre- and postmenopausal) aged 18-70 years were admitted 
to the General Clinical Research Center, UNC Chapel Hill and fed a standard diet containing a known amount of choline $(550 \mathrm{mg} / 70 \mathrm{~kg} /$ day; baseline $)$. On day 11, subjects were placed on a diet containing $<50 \mathrm{mg}$ choline/day for up to 42 days. Blood and urine were collected to measure various experimental parameters of dietary choline status, and markers of organ dysfunction and liver fat were assessed. If at some point during the depletion period functional markers indicated organ dysfunction associated with choline deficiency, subjects were switched to a diet containing choline until replete. Most men and postmenopausal women fed low choline diets under controlled conditions developed reversible fatty liver (measure by mass resonance spectroscopy) as well as liver and muscle damage, while $56 \%$ of premenopausal women were resistant to developing choline deficiency [22]. This observation immediately suggested that estrogen moderated the dietary requirement for choline, and, indeed, estrogen induces the gene (PEMT) that makes endogenous synthesis of choline possible [23]. The classic actions of estrogen occur through its receptors ER $\alpha$ and $\operatorname{ER} \beta$ which bind as homodimers or heterodimers to estrogen response elements (EREs) in the promoters of many estrogen-responsive genes [24]. The consensus ERE (PuGGTCAnnnTGACCPy) [24] and some imperfect ERE half site motifs (ERE1/2) bind with ER $\alpha$ and ER $\beta$ [25-27]. There are multiple EREs in the promoter region(s) of the PEMT gene [23] and estrogen caused a marked up-regulation in PEMT mRNA expression and enzyme activity in human hepatocytes [23]. Thus, premenopausal women have an enhanced capacity for de novo biosynthesis of choline moiety. During pregnancy, estradiol concentration rises from approximately 1 to $60 \mathrm{nM}$ at term [28, 29], suggesting that capacity for endogenous synthesis of choline is highest during the period when females need to support fetal development.

Pregnancy and lactation are times when demand for choline is especially high. Large amounts of choline are delivered to the fetus across the placenta, where choline transport systems pump it against a concentration gradient $[30,31]$ and deplete maternal plasma choline in humans [32]. Plasma or serum choline concentrations are 6- to 7-fold higher in the fetus and newborn than they are in the adult [33, 34]. High levels of choline circulating in the neonate presumably ensure enhanced availability of choline to tissues. It is interesting that despite enhanced capacity to synthesize choline, the demand for this nutrient is so high that stores are depleted during pregnancy. Pregnant rats had diminished total liver choline compounds compared to non-mated controls and become as sensitive to choline-deficient diets as were male rats [35]. Because milk contains a great deal of choline, lactation further increases maternal demand for choline, resulting in further depletion of tissue stores $[35,36]$. These observations suggest that women depend on high rates of PEMT activity, as well as on dietary intake of choline to sustain normal pregnancy. $\mathrm{Pemt}^{-1-}$ mice abort pregnancies at around 9-10 days of gestation unless fed supplemental choline (personal observation; [37]). As discussed later, choline nutriture during pregnancy is especially important because it influences brain development in the fetus [38-50]. 


\section{Genetic Variation in Dietary Requirements for Choline}

Though premenopausal women should be resistant to choline deficiency because of estrogen, a significant portion of them (44\%) developed organ dysfunction when deprived of choline [22]. Genetic variation likely underlies these differences in dietary requirements. As noted earlier, PEMT encodes for a protein responsible for endogenous formation of choline, and $78 \%$ of female carriers of the variant (C) allele in a SNP in the promoter region of the PEMT gene (rs12325817) developed organ dysfunction when fed a low choline diet (OR 25, p < 0.00005; p value based on 64 women studied) [51]. The frequency of this variant allele was 0.74 in North Carolina. The risk haplotype abrogated the induction of PEMT by estrogen, while the wild-type haplotype did not [Resseguie et al., manuscript submitted]. The SNP rs12325817 is not located in an estrogen response element but probably is in linkage disequilibrium with a functional SNP within such a response element.

Other SNPs in choline metabolism genes may have some influence on the dietary requirements for choline, though the $\mathrm{p}$ values for these associations are not as robust as for rs12325817. The first of 2 SNPs in the coding region of the choline dehydrogenase gene $(\mathrm{CHDH}$; rs9001) had a protective effect on susceptibility to choline deficiency, while a second $C H D H$ variant (rs12676) was associated with increased susceptibility [51]. We did not have the power in this study to identify any association of a SNP in the betaine:homocysteine methyltransferase gene (BHMT; rs3733890) with susceptibility to choline deficiency [51].

Genetic variants of genes in folate metabolism also modified the susceptibility of these subjects to choline deficiency [52]. Premenopausal women who were carriers of the very common 5,10-methylenetetrahydrofolate dehydrogenase-G1958A (MTHFD1; rs2236225) gene allele were more than 15 times as likely as non-carriers to develop signs of choline deficiency $(\mathrm{p}<0.0001)$ on the low choline diet. Sixty-three percent of our study population had at least 1 allele for this SNP. The rs2236225 polymorphism alters the delicately balanced flux between 5,10-methylene tetrahydrofolate and 10-formyl tetrahydrofolate and thereby influences the availability of 5-methyl THF for homocysteine remethylation [53]. This increases demand for choline as a methyl-group donor. It is of interest that the risk of having a child with a neural tube defect increases in mothers with the rs2236225 SNP [54]. We did not have sufficient power in the study to detect any effects of other folate metabolism SNPs (C677T and A1298C polymorphisms of the 5,10-methylene tetrahydrofolate reductase gene and the A80C polymorphism of the reduced folate carrier 1 gene) [52].

\section{Choline and Neural Development}

Rats and mice fed a low choline diet in late pregnancy (gestational days 12 to 17 in mice, days 12 to 18 or 20 in rats) had reduced neural progenitor cell proliferation and 
increased apoptosis in fetal hippocampus and cortex [38, 44, 55]. Similar outcomes were reported when pregnant mice are fed a low-folate diet [56], suggesting, again, potential synergistic mechanisms of action between folate and choline.

The mechanisms associating choline deficiency with decreased cell proliferation are, in part, related to the over-expression of cyclin-dependent kinase inhibitors (Cdkn) like p27Kip1 [40], p15Ink4b [40, 45] and Cdkn3 [45, 57], suggesting that choline deficiency inhibits cell proliferation by inducing $G_{1}$ arrest due to the inhibition of the interaction between cyclin-dependent kinases and cyclins. Using mouse hippocampal and cortical progenitor cells exposed to choline deficiency for $48 \mathrm{~h}$, oligonucleotide-array analysis of gene expression showed expression changes in more than a thousand genes, of which 331 were related to cell division, apoptosis, neuronal and glial differentiation, methyl metabolism, and calcium-binding protein ontology classes [58], consistent with the phenotype of reduced cell proliferation, increased apoptosis, and increased differentiation.

\section{Choline Deficiency Alters Gene Expression via Epigenetic Mechanisms}

Neural development is influenced by DNA methylation. Overall levels of methylation decrease as neuronal differentiation proceeds [59] and the treatment of neural progenitor cells with demethylating agents induces them to differentiate into cholinergic and adrenergic neurons [60]. Although the relationship between nutrition and epigenetics has been firmly established in the last few years [61], less is known about the role nutrition has in the epigenetic regulation of fetal brain development. Because dietary choline is an important player in the maintenance of the $S$-adenosylmethionine pool (the methyl donor for DNA methylation), along with folate and methionine, it is reasonable to expect that choline influences the epigenetic status of the developing brain. Global DNA methylation is decreased in the neuroepithelial layer of the hippocampus in choline deficient mouse fetal brains. Along with decreased global methylation, changes in gene-specific methylation were reported, where a cyclin-dependent kinase (Cdkn3) was hypo-methylated in its promoter by choline deficiency $[45,57]$ in the progenitor layer of the hippocampus. These alterations were associated with increased protein expression of this cyclin-dependent kinase inhibitor [45], and this model is consistent with previous findings showing that there is epigenetic regulation of cyclin-dependent kinase inhibitors that regulate cell proliferation [62].

\section{Long-Lasting Consequences of Prenatal Choline Availability}

The changes induced by dietary choline in fetal brain have long-lasting effects that alter brain function throughout life. Maternal dietary choline availability during late pregnancy was associated with long-lasting changes in the hippocampal function of the adult 
offspring. Choline supplementation during this period enhanced visuo-spatial and auditory memory in the adult rats throughout their life-span [63-67]. It also enhanced a property of the hippocampus, long-term potentiation $[46,68,69]$. The offspring from mothers fed a choline-deficient diet manifested opposite outcomes [64, 68].

\section{Implications for Human Brain Development}

It is always difficult to extrapolate findings reported using animal models to humans. However, limited data are available to support the hypothesis that similar mechanisms are involved in humans. Due to ethical constraints, no studies are available in children or pregnant mothers to validate the rodent model. Because the 2005 National Health and Nutrition Examination Survey (NHANES) data suggests that pregnant women do not consume adequate amounts of choline [18], and case-control studies in California suggest that women eating lower choline diets are at increased risk for giving birth to babies with neural tube defects [70] and cleft palate [71], the recommendation that pregnant women should attempt to consume diets adequate in choline seems reasonable. In addition, because half of the population has gene polymorphisms that affect choline and folate metabolism $[52,72]$, it is likely that different individuals may have different dietary requirements for choline and may need to pay special attention to choline intake during pregnancy.

\section{Acknowledgments}

This work was funded by grants from the National Institutes of Health (DK55865, AG09525). Support for this work was also provided by grants from the NIH to the UNC Nutrition \& Obesity Research Center (DK56350).

\section{References}

1 Chanock SJ, Manolio T, Boehnke M, et al: Replicating genotype-phenotype associations. Nature 2007;447: 655-660.

-2 Teo YY: Exploratory data analysis in large-scale genetic studies. Biostatistics 2010;11:70-81.

-3 Zeisel SH: Choline: critical role during fetal development and dietary requirements in adults. Annu Rev Nutr 2006;26:229-250.

-4 Niculescu MD, Zeisel SH: Diet methyl donors and DNA methylation: interactions between dietary folate methionine and choline. J Nutr 2002;132: 2333S-2335S

5 Finkelstein JD: Pathways and regulation of homocysteine metabolism in mammals. Semin Thromb Hemost 2000;26:219-225.
6 6 Kim Y-I, Miller JW, da Costa K-A, Nadeau M, Smith D, Selhub J, Zeisel SH, Mason JB: Folate deficiency causes secondary depletion of choline and phosphocholine in liver. J Nutr 1995;124:2197-2203.

-7 Selhub J, Seyoum E, Pomfret EA, Zeisel SH: Effects of choline deficiency and methotrexate treatment upon liver folate content and distribution. Cancer Res 1991;51:16-21.

\8 Varela-Moreiras G, Selhub J, da Costa K, Zeisel SH: Effect of chronic choline deficiency in rats on liver folate content and distribution. J Nutr Biochem 1992;3:519-522.

-9 Pomfret EA, da Costa K, Zeisel SH: Effects of choline deficiency and methotrexate treatment upon rat liver. J Nutr Biochem 1990;1:533-541. 


\section{Nutrigenetics Nutrigenomics}

\begin{tabular}{l|l}
\hline J Nutrigenet Nutrigenomics 2010;3:209-219 \\
\hline $\begin{array}{l}\text { DOI: 10.1159/000324357 } \\
\text { Published online: April 6, } 2011\end{array}$ & $\begin{array}{l}\text { @ } 2011 \text { S. Karger AG, Basel } \\
\text { www.karger.com/jnn }\end{array}$ \\
\hline
\end{tabular}

Zeisel: Clinical Nutrigenomics Approaches to Choline Functions and Requirements
10 Zeisel SH, Zola T, daCosta K, Pomfret EA: Effect of choline deficiency on $S$-adenosylmethionine and methionine concentrations in rat liver. Biochem J 1989;259:725-729.

-11 Varela-Moreiras G, Ragel C, Perez de Miguelsanz J: Choline deficiency and methotrexate treatment induces marked but reversible changes in hepatic folate concentrations serum homocysteine and DNA methylation rates in rats. J Amer Coll Nutr 1995; 14:480-485.

$\checkmark 12$ da Costa KA, Gaffney CE, Fischer LM, Zeisel SH: Choline deficiency in mice and humans is associated with increased plasma homocysteine concentration after a methionine load. Am J Clin Nutr 2005;81:440-444.

-13 Zeisel SH, Mar M-H, Howe JC, Holden JM: Concentrations of choline-containing compounds and betaine in common foods. J Nutr 2003;133:13021307.

14 Ilcol YO, Ozbek R, Hamurtekin E, Ulus IH: Choline status in newborns, infants, children, breast-feeding women, breast-fed infants and human breast milk. J Nutr Biochem 2005;16:489-499.

-15 Holmes-McNary MQ, Cheng WL, Mar MH, Fussell S, Zeisel SH: Choline and choline esters in human and rat milk and in infant formulas. Am J Clin Nutr 1996;64:572-576.

-16 Blusztajn JK, Zeisel SH, Wurtman RJ: Developmental changes in the activity of phosphatidylethanolamine $\mathrm{N}$-methyltransferases in rat brain. Biochem J 1985; 232:505-511.

17 Institute of Medicine and National Academy of Sciences USA: CholineIn Dietary Reference Intakes for Folate Thiamin Riboflavin Niacin Vitamin $\mathrm{B}_{12}$ Panthothenic Acid Biotin and Choline. Washington, National Academy Press, 1998, vol 1, pp 390-422

18 Jensen HH, Batres-Marquez SP, Carriquiry A, Schalinske KL: Choline in the diets of the US population: NHANES 2003-2004. FASEB J 2007;21: $1 \mathrm{~b} 219$.

19 Cho E, Zeisel SH, Jacques P, et al: Dietary choline and betaine assessed by food-frequency questionnaire in relation to plasma total homocysteine concentration in the Framingham Offspring Stud. Am J Clin Nutr 2006;83:905-911.

20 Busby MG, Fischer L, Da Costa KA, et al: Cholineand betaine-defined diets for use in clinical research and for the management of trimethylaminuria. J Am Diet Assoc 2004;104:1836-1845.

-21 da Costa KA, Badea M, Fischer LM, Zeisel SH: Elevated serum creatine phosphokinase in cholinedeficient humans: mechanistic studies in $\mathrm{C} 2 \mathrm{C} 12$ mouse myoblasts. Am J Clin Nutr 2004;80:163170 .
22 Fischer LM, da Costa K, Kwock L, et al: Sex and menopausal status influence human dietary requirements for the nutrient choline. Am J Clin Nutr 2007; 85:1275-1285.

23 Resseguie M, Song J, Niculescu M, da Costa K, Randall T, Zeisel S: Phosphatidylethanolamine $\mathrm{n}$-methyltransferase (PEMT) gene expression is induced by estrogen in human and mouse primary hepatocytes. FASEB J 2007;21:2822-2832.

24 Walter P, Green S, Greene G, et al: Cloning of the human estrogen receptor cDNA. Proc Natl Acad Sci USA 1985;82:7889-7893.

-25 Lopez D, Sanchez MD, Shea-Eaton W, McLean MP: Estrogen activates the high-density lipoprotein receptor gene via binding to estrogen response elements and interaction with sterol regulatory element binding protein-1A. Endocrinology 2002;143: 2155-2168.

26 Agarwal A, Yeung WS, Lee KF: Cloning and characterization of the human oviduct-specific glycoprotein (HuOGP) gene promoter. Mol Hum Reprod 2002;8:167-175.

27 Xie T, Ho SL, Ramsden D: Characterization and implications of estrogenic down-regulation of human catechol-O-methyltransferase gene transcription. Mol Pharmacol 1999;56:31-38.

28 Sarda IR, Gorwill RH: Hormonal studies in pregnancyI: total unconjugated estrogens in maternal peripheral vein cord vein and cord artery serum at delivery. Am J Obstet Gynecol 1976;124:234-238.

29 Adeyemo O, Jeyakumar H: Plasma progesterone estradiol-17beta and testosterone in maternal and cord blood and maternal human chorionic gonadotropin at parturition. Afr J Med Med Sci 1993;22:5560.

-30 Sweiry JH, Yudilevich DL: Characterization of choline transport at maternal and fetal interfaces of the perfused guinea-pig placenta. J Physiol 1985;366: 251-266.

- 31 Sweiry JH, Page KR, Dacke CG, Abramovich DR, Yudilevich DL: Evidence of saturable uptake mechanisms at maternal and fetal sides of the perfused human placenta by rapid paired-tracer dilution: studies with calcium and choline. J Devel Physiol 1986;8:435-445.

32 McMahon KE, Farrell PM: Measurement of free choline concentrations in maternal and neonatal blood by micropyrolysis gas chromatography. Clin Chim Acta 1985;149:1-12.

33 Zeisel SH, Wurtman RJ: Developmental changes in rat blood choline concentration. Biochem J 1981; 198:565-570.

34 Ozarda IY, Uncu G, Ulus IH: Free and phospholipid-bound choline concentrations in serum during pregnancy after delivery and in newborns. Arch Physiol Biochem 2002;110:393-399. 


\section{Nutrigenetics Nutrigenomics}

\begin{tabular}{l|l}
\hline J Nutrigenet Nutrigenomics 2010;3:209-219 \\
\hline $\begin{array}{l}\text { DOI: 10.1159/000324357 } \\
\text { Published online: April 6, 2011 }\end{array}$ & $\begin{array}{l}\text { @ 2011 S. Karger AG, Basel } \\
\text { www.karger.com/jnn }\end{array}$ \\
\hline
\end{tabular}

Zeisel: Clinical Nutrigenomics Approaches to Choline Functions and Requirements
- 35 Zeisel SH, Mar M-H, Zhou Z-W, da Costa K-A: Pregnancy and lactation are associated with diminished concentrations of choline and its metabolites in rat liver. J Nutr 1995;125:3049-3054.

-36 Holmes-McNary M, Cheng WL, Mar MH, Fussell S, Zeisel SH: Choline and choline esters in human and rat milk and infant formulas. Am J Clin Nutr 1996; 64:572-576.

-37 Zhu X, Mar MH, Song J, Zeisel SH: Deletion of the Pemt gene increases progenitor cell mitosis DNA and protein methylation and decreases calretinin expression in embryonic day 17 mouse hippocampus. Brain Res Dev Brain Res 2004;149:121-129.

- 38 Albright CD, Friedrich CB, Brown EC, Mar MH, Zeisel SH: Maternal dietary choline availability alters mitosis apoptosis and the localization of TOAD-64 protein in the developing fetal rat sep- 5 tum. Brain Res Dev Brain Res 1999;115:123-129.

- 39 Albright CD, Mar MH, Craciunescu CN, Song J, Zeisel SH: Maternal dietary choline availability alters the balance of netrin-1 and DCC neuronal migration proteins in fetal mouse brain hippocampus. Brain Res Dev Brain Res 2005;159:149-154.

-40 Albright CD, Mar MH, Friedrich CB, Brown EC, Zeisel SH: Maternal choline availability alters the localization of p15Ink4B and p27Kip1 cyclindependent kinase inhibitors in the developing fetal rat brain hippocampus. Dev Neurosci 2001;23:100106.

-41 Albright CD, Siwek DF, Craciunescu CN, et al: Choline availability during embryonic development alters the localization of calretinin in developing and aging mouse hippocampus. Nutr Neurosci 2003;6:129-134.

-42 Albright CD, Tsai AY, Friedrich CB, Mar MH, Zeisel SH: Choline availability alters embryonic development of the hippocampus and septum in the rat. Brain Res Dev Brain Res 1999;113:13-20.

-43 Albright CD, Tsai AY, Mar M-H, Zeisel SH: Choline availability modulates the expression of TGFß1 and cytoskeletal proteins in the hippocampus of devel- 56 oping rat brain. Neurochem Res 1998;23:751-758.

-44 Craciunescu CN, Albright CD, Mar MH, Song J, Zeisel SH: Choline availability during embryonic development alters progenitor cell mitosis in developing mouse hippocampus. J Nutr 2003;133:36143618.

-45 Niculescu MD, Craciunescu CN, Zeisel SH: Dietary choline deficiency alters global and gene-specific DNA methylation in the developing hippocampus of mouse fetal brains. FASEB J 2006;20:43-49.

-46 Pyapali G, Turner D, Williams C, Meck W, Swartzwelder HS: Prenatal choline supplementation decreases the threshold for induction of long-term potentiation in young adult rats. J Neurophysiol 1998;79:1790-1796.
Meck W, Williams C: Perinatal choline supplementation increases the threshold for chunking in spatial memory. Neuroreport 1997;8:3053-3059.

48 Meck WH, Smith RA, Williams CL: Pre- and postnatal choline supplementation produces long-term facilitation of spatial memory. Dev Psychobiol 1988; 21:339-353.

49 Meck WH, Williams CL: Metabolic imprinting of choline by its availability during gestation: implications for memory and attentional processing across the lifespan. Neurosci Biobehav Rev 2003;27:385399.

50 Mellott TJ, Williams CL, Meck WH, Blusztajn JK: Prenatal choline supplementation advances hippocampal development and enhances MAPK and CREB activation. FASEB J 2004;18:545-547.

da Costa KA, Kozyreva OG, Song J, et al: Common genetic polymorphisms affect the human requirement for the nutrient choline. FASEB J 2006;20:13361344.

52 Kohlmeier M, da Costa KA, Fischer LM, Zeisel SH: Genetic variation of folate-mediated one-carbon transfer pathway predicts susceptibility to choline deficiency in humans. Proc Natl Acad Sci USA 2005; 102:16025-16030.

53 Horne DW: Neither methionine nor nitrous oxide inactivation of methionine synthase affect the concentration of 510-methylenetetrahydrofolate in rat liver. J Nutr 2003;133:476-478.

54 Brody LC, Conley M, Cox C, et al: A polymorphism R653Q in the trifunctional enzyme methylenetetrahydrofolatedehydrogenase/methenyltetrahydrofolate cyclohydrolase/formyltetrahydrofolate synthetase is a maternal genetic risk factor for neural tube defects: report of the Birth Defects Research Group. Am J Human Genet 2002;71:1207-1215.

55 Holmes-McNary MQ, Loy R, Mar MH, Albright $\mathrm{CD}$, Zeisel SH: Apoptosis is induced by choline deficiency in fetal brain and in PC12 cells. Brain Res Dev Brain Res 1997;101:9-16.

6 Craciunescu CN, Brown EC, Mar MH, et al: Folic acid deficiency during late gestation decreases progenitor cell proliferation and increases apoptosis in fetal mouse brain. J Nutr 2004;134:162-166.

57 Niculescu MD, Yamamuro Y, Zeisel SH: Choline availability modulates human neuroblastoma cell proliferation and alters the methylation of the promoter region of the cyclin-dependent kinase inhibitor 3 gene. J Neurochem 2004;89:1252-1259.

58 Niculescu MD, Craciunescu CN, Zeisel SH: Gene expression profiling of choline-deprived neural precursor cells isolated from mouse brain. Brain Res Mol Brain Res 2005;134:309-322.

Costello JF: DNA methylation in brain development and gliomagenesis. Front Biosci 2003;8:s175-s184. 


\section{Nutrigenetics \\ Nutrigenomics}

\begin{tabular}{l|l}
\hline J Nutrigenet Nutrigenomics 2010;3:209-219 \\
\hline DOI: 10.1159/000324357 & $\begin{array}{l}\text { @ 2011 S. Karger AG, Basel } \\
\text { www.karger.com/jnn }\end{array}$ \\
Published online: April 6, 2011 &
\end{tabular}

Zeisel: Clinical Nutrigenomics Approaches to Choline Functions and Requirements
60 Mattson MP: Methylation and acetylation in nervous system development and neurodegenerative disorders. Ageing Res Rev 2003;2:329-342.

61 Feil R: Environmental and nutritional effects on the epigenetic regulation of genes. Mutation Research/ Fundamental and Molecular Mechanisms of Mutagenesis 2006;600;46-57.

62 Fukai K, Yokosuka O, Imazeki F, et al: Methylation status of p14ARF p15INK4b and p16INK4a genes in human hepatocellular carcinoma. Liver International 2005;25:1209-1216.

63 Meck WH, Williams CL: Perinatal choline supplementation increases the threshold for chunking in spatial memory. Neuroreport 1997;8:3053-3059.

64 Meck WH, Williams CL: Simultaneous temporal processing is sensitive to prenatal choline availability in mature and aged rats. Neuroreport 1997;8: 3045-3051.

65 Meck WH, Williams CL: Characterization of the facilitative effects of perinatal choline supplementation on timing and temporal memory. Neuroreport 1997;8:2831-2835.

-66 Meck WH, Williams CL: Choline supplementation during prenatal development reduces proactive interference in spatial memory. Brain Res Dev Brain Res 1999;118:51-59.
67 Williams CL, Meck WH, Heyer DD, Loy R: Hypertrophy of basal forebrain neurons and enhanced visuospatial memory in perinatally choline-supplemented rats. Brain Res 1998;794:225238.

68 Jones JP, Meck W, Williams CL, Wilson WA, Swartzwelder HS: Choline availability to the developing rat fetus alters adult hippocampal long-term potentiation. Brain Res Dev Brain Res 1999;118:159167.

-69 Montoya DA, White AM, Williams CL, et al: Prenatal choline exposure alters hippocampal responsiveness to cholinergic stimulation in adulthood. Brain Res Dev Brain Res 2000;123:25-32.

70 Shaw GM, Carmichael SL, Yang W, Selvin S, Schaffer DM: Periconceptional dietary intake of choline and betaine and neural tube defects in offspring. Am J Epidemiol 2004;160:102-109.

71 Shaw GM, Carmichael SL, Laurent C, Rasmussen SA: Maternal nutrient intakes and risk of orofacial clefts. Epidemiology 2006;17:285-291.

72 da Costa KA, Kozyreva OG, Song J, et al: Common genetic polymorphisms affect the human requirement for the nutrient choline. Faseb J 2006;20:13361344 . 